\title{
Awareness of antibiotic usage and antimicrobial resistance among interns in a tertiary care hospital
}

\author{
Suchitra D. Akalu*, Niveditha G. Belavadi
}

Department of Pharmacology, ESIC-MC and PGIMSR, Rajajinagar, Bengaluru, Karnataka, India

Received: 03 June 2017

Revised: 12 June 2017

Accepted: 29 June 2017

*Correspondence to:

Dr. Suchitra D. Akalu,

Email: suchisham@hotmail.com

Copyright: (C) the author(s), publisher and licensee Medip Academy. This is an openaccess article distributed under the terms of the Creative Commons Attribution NonCommercial License, which permits unrestricted noncommercial use, distribution, and reproduction in any medium, provided the original work is properly cited.

\begin{abstract}
Background: Antibiotic resistance is a global threat and new resistance mechanisms are emerging and spreading globally, threatening our ability to treat common infectious diseases. Reducing the incidence of drug resistant infections is crucial and is a top priority at global and national levels. A study was conducted among interns to assess the awareness related to antibiotic usage and resistance. Methods: The questionnaire was administered to a batch of 75 medical interns whereby their awareness regarding antibiotic use and resistance was assessed by a five point Likert scale, whose responses ranged from "strongly agree" to "strongly disagree", and always to never. Some questions were of true and false type. The data was analysed by using simple descriptive statistics.

Results: Out of the 78 interns, 75 participated in the study and completed the questionnaires. All the $75(100 \%)$ interns believed that indiscriminate antibiotic use leads to antimicrobial resistance and $78.6 \% \quad(n=59)$ believed that if antimicrobials are taken too often, they are less likely to work in the future. Majority (90.6\%) of the interns knew of the fact that common cold and influenza are due to viral aetiology and not bacterial. Regarding the antibiotic practices of the interns, questionnaire addressed questions related to their practices related to use of antimicrobials, $66.6 \%(n=50)$ of the interns disagreed on the question that antibiotics are safe drugs, hence can be commonly used while $62.6 \%(n=47)$ do not believe that skipping one or two doses of the drug does not lead to antibiotic resistance.

Conclusions: The antibiotic resistance crisis has been attributed to the overuse and misuse of these medications. Judicious use of antibiotics is the only solution for which awareness is required at the level of both health care providers and patients. Our study provides an important insight regarding the regarding awareness of antibiotic usage and antibiotic resistance among interns.
\end{abstract}

Keywords: Antibiotic resistance, Antibiotic usage, Interns

\section{INTRODUCTION}

Antibiotic resistance is rising to dangerously high levels in all parts of the world. New resistance mechanisms are emerging and spreading globally, threatening our ability to treat common infectious diseases. ${ }^{1}$ Reducing the incidence of drug resistant infections is crucial and is a top priority of the World Health Organization (WHO), pharmaceutical industry, and many national health agendas. ${ }^{2-7} \mathrm{~A}$ major driver of drug resistance is antibiotic misuse, which is pervasive worldwide. Misuse contributes to the spread of multidrug resistant organisms (MDROs). ${ }^{2}$ Infections caused by MDROs result in longer hospital stays and increased morbidity and mortality. ${ }^{8}$ In India, MDROs are responsible for over 58,000 deaths each year in the neonate population alone. ${ }^{7}$

Antibiotic resistance is accelerated by the misuse and overuse of antibiotics, as well as poor infection prevention and control. Steps can be taken at all levels of society to reduce the impact and limit the spread of resistance. A global action plan on antimicrobial resistance, was endorsed at the World Health Assembly in May 2015. The global action plan aims to ensure prevention and treatment of infectious diseases with safe and effective medicines. The "Global action plan on antimicrobial resistance" has five strategic objectives which include improving 
awareness and understanding of antimicrobial resistance, to strengthen surveillance and research, to reduce the incidence of infection, to optimize the use of antimicrobial medicines and to ensure sustainable investment in countering antimicrobial resistance. ${ }^{1}$

Ministry of Health and Family Welfare in India also aims at reducing the problem of irrational use of antibiotics and curb antimicrobial resistance. As per National Health Policy 2017, Ministry of Health and Family Welfare "Pharmacovigilance includes Prescription Audit inclusive of Antibiotic usage, in the hospital and community is a must in order to enforce change in existing practices". ${ }^{8}$ As part of this action plan, to increase the awareness and understanding of antimicrobial resistance, a sensitization session on rational use of drugs with emphasis on antibiotics was conducted in ESIC-MC and PGIMSR, Bangalore for the interns who had just completed about seven days of internship. A questionnaire was administered to evaluate the awareness about antibiotic usage and resistance among the interns.

\section{METHODS}

This cross-sectional questionnaire-based survey was conducted in ESIC-MC and PGIMSR among the 78 interns during the month of March 2017. A pre-validated questionnaire which was used by Manali $M$ et al was distributed before the talk on rational use of antibiotics and 20 minutes of time was given to complete the task. ${ }^{9}$ Responses was assessed by a five point Likert scale, whose responses ranged from "strongly agree" to "strongly disagree", and always to never. Some questions were of true and false type. They were asked to complete the questionnaire anonymously. Interns who were willing to participate in the study were only included.

In order to simplify the analysis, the five point response options of the Likert scale were reduced into three, such as true/false/uncertain, agree/disagree/uncertain and yes/no/uncertain. The possible answers "strongly agree" and "agree" were considered as a "positive" answer, while the possible answers "disagree" and "strongly disagree" were considered as a "negative" answer and remaining were uncertain. The possible answers "always" and "usually" were considered as a "yes" answer, while the possible answers "never" were considered as a "no" answer and possible answers "sometimes" were considered as uncertain. The data was analysed by using simple descriptive statistics.

\section{RESULTS}

Out of the 78 interns, 75 participated in the study and completed the questionnaires. All the 75 (100\%) interns believed that indiscriminate antibiotic use leads to antimicrobial resistance. $78.6 \%(n=59)$ believed that if antimicrobials are taken too often, they are less likely to work in the future. Majority $(90.6 \%)$ of the interns knew of the fact that common cold and influenza are due to viral aetiology and not bacterial. $67(89.3 \%)$ of the interns felt that antibiotic resistance is an important and serious global public health issue. Most of the interns (97.3\%) had the knowledge that ineffective treatment can occur due to indiscriminate and injudicious antimicrobial use (Figure 1).

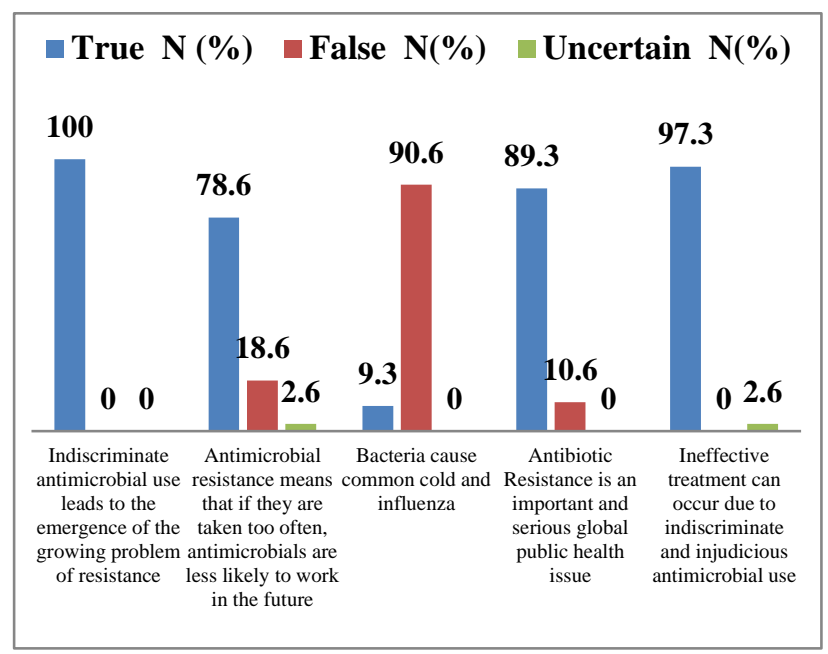

Figure 1: Questionnaire assessed the students knowledge about antibiotic resistance and usage.

Regarding the antibiotic practices of the interns, questionnaire addressed questions related to their practices of antimicrobials use. $66.6 \% \quad(n=50)$ of the interns disagreed on the question that antibiotics are safe drugs while $62.6 \%(n=47)$ do not believe that skipping one or two doses of the drug does not lead to antibiotic resistance. $60 \%(n=45)$ of the interns disagreed that adverse effects of antimicrobials can be reduced by using more than one antimicrobial at a time. Majority of them $(94.6 \%(n=71)$ disagreed on injudicious use of antimicrobials shortens the duration of illness. $92 \%(n=69)$ were of the opinion that antibiotics are the not the first choice for cough and sore throat (Figure 2).

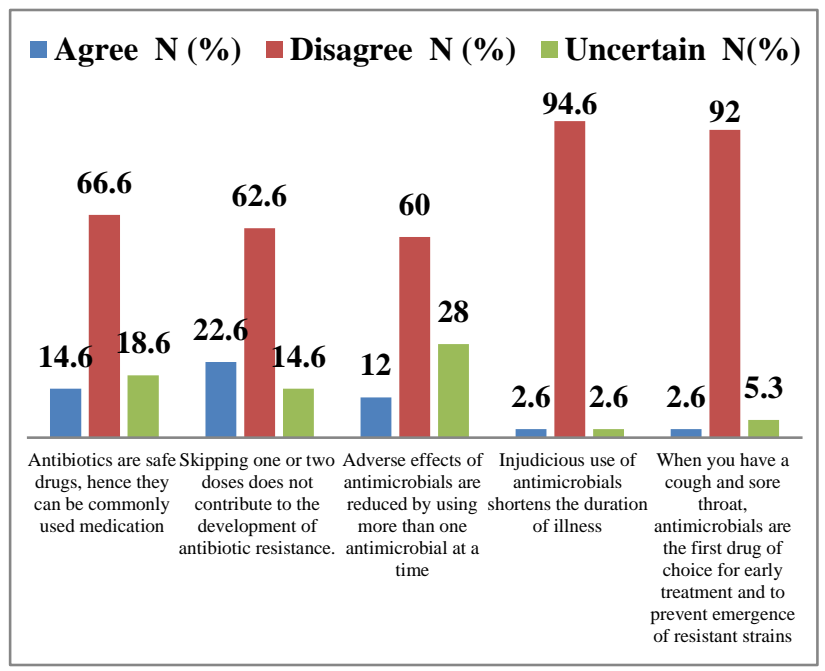

Figure 2: Questionnaire addressed questions related to their practices related to use of antimicrobials. 
Majority of the interns did have healthy practices with regard to completing the course of antibiotic treatment, not giving left over antibiotics to others, consulting a doctor for treatment, checking the expiry date and not taking antibiotics for sore throat. The results are summarized in Table $1.68 \%(n=51)$ of the interns did not want to discard the remaining left over medication while $10.6 \%$ were not sure as what to do with left over medication.

Table 1: Awareness of the interns regarding antibiotic usage.

\begin{tabular}{|lllll|}
\hline & The doctor prescribes a course of antibiotic for you. After taking & Yes & No & Uncertain \\
\hline 2-3 doses you start feeling better & $\mathbf{N}(\%)$ & N (\%) & $\mathbf{N}(\%)$ \\
\hline (a) & Do you stop taking the further treatment? & $02(2.6)$ & $71(94.6)$ & $02(2.6)$ \\
\hline (b) & Do you save the remaining antibiotics for the next time you get sick? & $04(5.3 \%)$ & $69(92)$ & $02(2.6)$ \\
\hline (c) & Do you discard the remaining, left over medication? & $16(21.3)$ & $51(68)$ & $08(10.6)$ \\
\hline (d) & $\begin{array}{l}\text { Do you give the left over antibiotics to your friend/roommate if they } \\
\text { get sick? }\end{array}$ & $06(8)$ & $66(88)$ & $03(4)$ \\
\hline (e) & Do you complete the full course of treatment? & $72(96)$ & $03(4)$ & 0 \\
\hline (f) & Do you consult a doctor before starting an antibiotic? & $73(97.3)$ & $02(2.6)$ & 0 \\
\hline (g) & Do you check the expiry date of the antibiotic before using it? & $100(100)$ & 0 & 0 \\
\hline (h) & $\begin{array}{l}\text { Do you prefer to take an antibiotic when you have cough and sore } \\
\text { throat? }\end{array}$ & $06(8)$ & $69(92)$ & 0 \\
\hline
\end{tabular}

$97.3 \%$ of the interns felt that awareness about rational use of antibiotics can be encouraged in patients by organizing public health campaigns. $92 \%$ of them felt that judicious, careful and rational use of medicines must be followed and recommended. $96 \%$ of the interns felt that full course of antimicrobials in the prescribed dose has to be completed. $90.6 \%$ were of the opinion that antibiotics have to be prescribed based on culture-sensitivity reports. Results of all the questions related to solution to the problem of antimicrobial resistance are summarized in Table 2.

Table 2: Awareness of the interns regarding antibiotic resistance.

\begin{tabular}{|ll|}
\hline Questions & Response \\
\hline $\begin{array}{l}\text { Judicious, careful and rational use of } \\
\text { medicines }\end{array}$ & $69(92 \%)$ \\
\hline $\begin{array}{l}\text { Complete the full course of } \\
\text { antimicrobials in the prescribed dose }\end{array}$ & $72(96 \%)$ \\
\hline Avoid self-medication & $71(94.6 \%)$ \\
\hline Multidrug therapy & $48(64 \%)$ \\
\hline $\begin{array}{l}\text { Symptomatic management in self- } \\
\text { limiting conditions }\end{array}$ & $67(89.3 \%)$ \\
\hline $\begin{array}{l}\text { Awareness among patients by organising } \\
\text { public health campaigns }\end{array}$ & $73(97.3 \%)$ \\
\hline No response & $09(12 \%)$ \\
\hline Prescribe using culture sensitivity reports & $68(90.6 \%)$ \\
\hline New drug discovery & $47(62.6 \%)$ \\
\hline
\end{tabular}

\section{DISCUSSION}

Antibiotics are among the most commonly prescribed drugs used in human medicine and can be lifesaving drugs. ${ }^{10}$ However, up to $50 \%$ of the time antibiotics are not optimally prescribed, often done so when not needed, incorrect dosing or duration. Rational use of medicines
(RUM) is recognised as an important factor in health policy. RUM requires that patients receive medications appropriate to their clinical needs, in doses that meet their own individual requirements, for an adequate period of time, and at the lowest cost to them and their community. ${ }^{1}$ WHO estimates that more than half of all medicines are prescribed, dispensed or sold inappropriately, and that half of the patients fail to take them correctly. ${ }^{11}$

In this study, totally 75 interns completed the questionnaire and all the interns were aware of the problem of antimicrobial resistance globally. Majority of them were responsible while using the antibiotics and the practices reported by them was found to be satisfactory in our study. This finding is similar to a study conducted by Manali M, et al. Majority of the interns consulted the doctor before taking antibiotics though over the counter (OTC) is highly prevalent in India with regard to antibiotics. This finding is similar to the study of Manali M, et al and is in contrast to a study conducted by Azevedo MM et al where selfmedication was prevalent. ${ }^{12}$

In our study, majority of the students were aware of the fact that influenza and common cold are due to viral aetiology and not bacterial. This finding is similar to study conducted by Manali M et al. $92 \%$ of the interns in our study felt that antibiotic need not be the first choice for sore throat and cough. This is in contrast to a study conducted in students by Manali M et al where only $46 \%$ of students felt that antibiotic is the not the first choice. With regard to solution for antimicrobial resistance, interns were responsible in choosing the answers and majority of them felt that judicious use, avoiding self-medication, creating awareness among patients about taking full course of antibiotics, prescribing using culture-sensitivity reports were essential in curbing the antimicrobial resistance. 


\section{CONCLUSION}

The rapid emergence of resistant bacteria is occurring worldwide, endangering the efficacy of antibiotics, which have transformed medicine and saved millions of lives. Many decades after the first patients were treated with antibiotics; bacterial infections have again become a threat. The antibiotic resistance crisis has been attributed to the overuse and misuse of these medications. Judicious use of antibiotics is the only solution for which awareness is required at the level of health care providers and patients. Our study provides an important insight regarding the knowledge, attitudes and practices regarding antibiotic resistance and usage among interns.

\section{ACKNOWLEDGEMENTS}

Authors would like to thank the Dean, Faculty and the Medical education unit for the support.

Funding: No funding sources

Conflict of interest: None declared

Ethical approval: The study was approved by the Institutional Ethics Committee

\section{REFERENCES}

1. Antibiotic resistance. Available at: http://www.who.int/mediacentre/factsheets/antibiotic -resistance/en/. Accessed on 24 April 2017

2. Antimicrobial Resistance: Global Report on Surveillance. World Health Organization. 2014. Available at: http://www.who.int/drugresistance/documents/surveil lancereport/en/. Accessed 12 Nov 2014.

3. Antibiotic Resistance Threats in the United States. Centers for Disease Control. 2013. Available at: http://www.cdc.gov/drugresistance/threat-report2013/. Accessed 12 Nov 2014.

4. UK Five Year Antimicrobial Resistance Strategy, 2013 to 2018. Department of Health and Department for Environmental Food and Rural Affairs. 2013. Available at: https://www.gov.uk/government/publications/uk-5- year-antimicrobial-resistance-strategy-2013-to-2018. Accessed 20 Feb 2016.

5. Ghafur A, Mathai D, Muruganathan A, Jayalal JA, Kant R, Chaudhary D, et al. The Chennai declaration: a roadmap to tackle the challenge of antimicrobial resistance. Indian J Cancer. 2013;50:71-3.

6. Declaration by the Pharmaceutical, Biotechnology and Diagnostics Industries on Combating Antimicrobial Resistance. World Economic Forum, Davos Switzerland. 2016. Available at: https://amrreview.org/sites/default/files/Declaration_of_Support _for_Combating_AMR_Jan_2016.pdf. Accessed on 25 Feb 2016.

7. Laxminarayan R, Duse A, Wattal C, Zaidi AKM, Wertheim HFL, Sumpradit N, et al. Antibiotic resistance - the need for global solutions. Lancet Infect Dis. 2013; 13:1057-98.

8. National Health Policy 2017. Available at: http://www.mohfw.nic.in/showfile.php?lid=4275. Accessed on 25 April 2017

9. Manali M, Sujatha D, Swapnil D. A Questionnaire based Survey on the Knowledge, Attitude and Practises about Antimicrobial Resistance and Usage among the Second year MBBS Students of a Teaching tertiary care Hospital in Central India. International Journal of Pharmacological Research. 2014;4(4):1759.

10. CDC Antibiotic / Antimicrobial Resistance. Available at: https://www.cdc.gov/drugresistance/about.html. Accessed on 25April 2017.

11. The Pursuit of Responsible Use of Medicines: Sharing and Learning from Country Experiences. Available at: http://apps.who.int/iris/bitstream/10665/75828/1/WH O_EMP_MAR_2012.3_eng.pdf. 24 April 2017.

12. Azevedo MM, Pinheiro C, Yaphe J, Baltazar F. Portuguese students knowledge of antibiotics: a crosssectional study of secondary school and university students in Braga. BMC Public Health. 2009;9:359.

Cite this article as: Akalu SD, Belavadi NG.

Awareness of antibiotic usage and antimicrobial resistance among interns in a tertiary care hospital. Int J Basic Clin Pharmacol 2017;6:2159-62. 